\title{
Development as Crossing: An Anthropological Approach
}

\section{Claver Boundja}

Philosophy of Development, Governance and Development Laboratory (GDL), Marien Ngouabi University, Brazzaville, Republic of Congo

Email: claverboundja@gmail.com

How to cite this paper: Boundja, C. (2019) Development as Crossing: An Anthropological Approach. Advances in Anthropology, 9, 32-55.

https://doi.org/10.4236/aa.2019.91003

Received: October 17, 2018

Accepted: January 8, 2019

Published: January 11, 2019

Copyright (c) 2019 by author(s) and Scientific Research Publishing Inc. This work is licensed under the Creative Commons Attribution International License (CC BY 4.0).

http://creativecommons.org/licenses/by/4.0/

\begin{abstract}
This article proposes an anthropological reflection about development, in the philosophical sense of the term. Contemporary philosophers seem to be far from the question of development, which is an essential question for the societies of our time. It is therefore urgent to enunciate a theory of development, anthropological reflection that lies beyond economic and political theories on development. It is necessary to think about development, in its link with humanity or the essence of the human, by leading it to the element of its truth, namely the individual well-being, which escapes all attempts at control, probability and econometrics. This article proposes a new paradigm of development calls for a fundamental reflection, based on the analysis of human consciousness. We examine human consciousness, to understand its foundations about crossing, in a discourse with a universal aim.
\end{abstract}

\section{Keywords}

Development, Philosophical Anthropology, Well-Being, Consciousness, Human Being

\section{Introduction}

The question of economic and social development is now relevant. Scholars have produced detailed accounts describing a history of development theories and schools of thought (Rist, 1997; Kothari, 2005). “Theorizing about development can depart from normative or empirical bases, from moral principles and values relating to a desirable society or from evidence about how societies have changed over time. In practice, the theoretical and empirical lines of thought are intertwined and many scholars speak to the interplay between the two" (Bruce, 2016: p 9). Development studies have historical roots that stretch across time con- 
necting different thinkers and eras. Aristotle thinks the concept of "flourishing lives" long before contemporary scholarship on capabilities (Nussbaum, 1988). The themes which are today treated very widely in philosophical anthropology are found in Aristotle's De anima, in Ethics, Rhetoric, Politics and Poetics. The three books on the soul are part of the second philosophy as theoretical epistemology, ethics is part of practical epistemology, and the other books relate to "aptitudes".

Thus, according to Aristotle, human being is the subject of theoretical and practical disciplines. In these disciplines, the fundamental determinations of human being are not acquired independently, but developed on the one hand in the doctrine of the multiple ways in which being is said (categories) on the other hand in the first philosophy (later named metaphysical). Following Aristotle, our reflection on the development of a point of view of philosophical anthropology insists on the idea that every human being can have on his well-being: what does it mean to be good and how to realize it as an individual? We show that the philosophy of human development is based on the answer to the following four questions posed by Ernst Bloch: "Who are we? Where do we come from? Where are we going? What are we waiting for? What awaits us?" (Bloch, 1986: p. 3).

In general, development studies have been defined as knowledge and understanding of the world in which we live (Sen, 2005). Informed by practice and facts on the ground, it includes ideas, concepts and theories that constitute our knowledge of how societies change. What things change and how they change are all the results of what people choose to do. These choices are shaped by the ideas people hold and debate (Beland \& Cox, 2011). The development news conveys a form of unanimity that considers this concept as self-evident and, as such, it does not require a thorough examination.

This lack of reflection raises an ethical problem. If ethics is associated with the well-being of the individual in society, it should have a natural link with human development, understood as a qualitative and quantitative improvement of the living conditions of the human being. But development has remained on the periphery of contemporary philosophy. He is thus devoted to the calculating game of politics in their conquest of power, weaved in the middle between the probabilistic and the uncertainty of the economists. In political and economic circles, we have moved from the notion of development to that of human development, and then to that of sustainable development, far from a question of background.

In the ordinary sense, development is the action of developing (organism, organ); the evolution of what is developing, that is, growing. The concept of development, from the historical point of view, appears in a position or a game of opposition to underdevelopment, which would be its lower level, characterized by a global societal insufficiency of well-being.

But what would be the criterion of accession to development? Is it possible to envisage, at the purely theoretical level, a state of developed society? To consider yourself as already developed is it not a sign of death or cessation of the possi- 
bility of any novelty? Anyway, development cannot be a stable state to achieve, but an opening to the future of man, the world and history; a welcome of what comes endlessly as a possibility of a good life with and for others, in us and outside of us. Thus understood, development is the insertion of the soul into matter, the entry of meaning into the substratum of the change of the world, so long as matter is understood, with Aristotle, as the substratum of change.

The concept of development, applied to the economic and the social, carries a unilateral progressive ideology which sometimes induces practical behaviors contrary to the interest of the populations judged "underdeveloped", according to quantitative statistical criteria that only account for part of the social. Thought and presented according to the tables of statisticians, the development does not account for the situation of singular persons.

This global, rationalist, humanitarian conception of becoming has too often had disastrous repercussions for the companies to which it has been applied. It is therefore urgent to think of another concept of development, much more concerned with the total good of man.

Today, the ecological crisis, which is basically a crisis of civilization, has worsened. Industrial civilization, with its unlimited productivity, appears to be responsible not only for the exponential growth of air, land and water pollution, but also for attacks, perhaps irreversible, on the ecological system of the planet. And the concept of "sustainable development", which promotes» sustainable exploitation» resources of nature, is not a solution to this crisis. The real solution to the problem of the ecological crisis will be the change, from top to bottom, of the current mode of production and consumption, generating inequalities and disasters. To prevent the increasing degradation of the environment, it is necessary to break with an economic logic that knows only the law of the market, profit and accumulation.

Since the end of the twentieth century, considering freedom as a primary and ultimate end of development, Amartya Sen (1999) defines it as overcoming all obstacles that restrict men's choices and prevent them from acting freely. Development thus corresponds to access to all forms of individual, economic, social, cultural and political freedom. Amartya Sen intends to release the development of a design based on the measurement of economic indicators (growth of gross national product, increase of incomes, industrialization, progress of technology, social modernization) to focus on the well-being of the economy individual and his ability to act freely.

This research aims to answer these interrogations: what does development mean and for what development? Who is human being, and what is his future? These interrogations guide the two parts of this work, to present a general theory of development based on a certain understanding of man (anthropology); and think about the future (what happens to us) from becoming (what we bring to the world). The philosophy of human development, thus initiated, is not limited to the economic and social aspects of this notion. It presents the postulates that 
give development meaning, and deduces are the conditions that door its essence and purpose. From the point of view of meaning, the world is not a mere geographical and spatial territory, but the whole constituted by human activities and consumable goods.

\section{Philosophical Anthropology of Development}

The starting point of any philosophy must be his self-justification, for latent reason is called to be brought to the understanding of its own possibilities, according to a coherent apodictic method. This first point sets itself the task of clarifying the principles of all philosophy, coupled with the anthropology of development. It should be remembered that since Immanuel Kant, philosophy, as an activity of human reason, is reduced to anthropology (Kant, 1819).

In a condensed formula, Ernst Bloch summarizes the essence of philosophy: “Thinking means going over" (Bloch, 1986: p. 10). Thinking his crossing, which indicates the transition from a lower level to a higher level and, as such, is the other name of development of human being. To cross, by thinking, is to pass from a sedimentary, stable and crystallized conception of existence to a thought of the open, tense towards what is incessantly in action and power in the world. The act of thinking is a surpassing of oneself, which welcomes and follows the fluvial course of things. It is a question of assuming, from a philosophical point of view, "the hope located in the world" (Bloch, 1986: p. 13), for a conquest of man by himself.

Such an assumption requires an evaluation of the history of philosophy as a history of forgetting the Not-yet-become. Blochian thought intends to assume novelty both as a philosophical act and as a content of thought to think is to follow the movement of the New. Here there is a dimension of development to be grasped, that which concerns the displacement or the odyssey of a static vision of the world to a dynamic conception of the world, within the thinking subject. It is advisable to insist on the thinking subject, because the philosophical approach is not intended to become an applied science capable of solving the immediate problems of human existence.

The upsurge of the philosophy of development follows the movement of departure or crossed of classical ontology. The concept of development which concerns us in this study is that which comes from the socio-economic area, more precisely from that of international economic relations. But we can define development, from the point of view of philosophical anthropology, as a vision of the world. In this context, development does not refer only to a process and measurable results, in economic, social, political and cultural transformations, or to a form of social change. It is also an ideology, a vision of the world strongly impregnated by positivism and determinism.

It is as a vision of the world that development requires adequate philosophical analysis, so that it is grounded in reason: how to understand the commonly accepted principles underlying the concept of development? The philosophy of 
development, insofar as it intends to deal with a sectional issue of human existence, must first specify its relations with the first philosophy or the first science, brought back by Martin Heidegger to fundamental ontology. Such a task certainly has a theoretical and epistemological character, but it is above all prolegomena, in so far as it is necessary to begin by laying the foundations of the first philosophy itself, it is necessary to found in reason what can serve from foundation to the anthropology of development. In the book E of Metaphysics (2.1026-a 33-b 2), Aristotle develops the different possibilities of enunciating being. He presents the unity of being as a unit of analogy, for being is said in various ways (Aristotle, 1801). To grasp the being as being, in its being, such is the task of metaphysics or of the first science.

The primacy of ontology would be a priority and a base on and from which the whole architecture of science can be developed. The first philosophy itself has a beginning, that is to say, a moment and a place where it comes to light, and passes into the element of its own method and object. Through this passage, it inaugurates all science. To speak of a beginning presupposes, at least, that the first philosophy has not always been, that it is not self-evident, that it is distinguished from what it is not, by qualities peculiar to it, and allow it to decline his identity in truth.

In short, the first philosophy, opening up and offering itself under the species of path, opens the way to philosophy or science in general. Our aim, in these lines, is not to found the first science, but to start from the contours defined by M. Heidegger, to suggest the bases of the anthropology of development, thought from the Blochian concept of Novum (New).

The main interest of the Heideggerian approach lies in the fact that he brings back the reflection on ontology in the daily life of mankind or human facticity. Ontology is thus linked to the structure of life and intends to be concretely verified in experience. From the phenomenological point of view, facticity is a transcendental moment (in the Kantian sense of possibility condition) that can be concretely affirmed in experience.

We start from Heidegger in the manner of a ship to leave port, must break the ties that bound the riveted to that port; go of, as a way of getting away. It is Emmanuel Levinas that should be invited to operate this departure. According to E. Levinas, the resumption of ontology by contemporary philosophy leads to a fundamental affirmation: "All human being is ontology. His scientific work, his emotional life, the satisfaction of his needs and his work, his social life and his death articulate, with a rigor that reserves for each of these moments a specific function, the understanding of being or the truth. (...) It is not because there is man that there is truth. It is because being is inseparable from its truth (...) because being is intelligible that there is humanity" (Levinas, 1993: p. 13).

Now, with Heidegger, the understanding of being is not limited only to the register of theoretical attitudes, but extends everywhere, because the ontology here is understood as the essence of any relationship with being: "Our concrete existence is interpreted according to its entry into the "open to be in general. We 
exist in a circuit of intelligence with the real-intelligence is the very event that existence articulates" (Levinas, 1993: p. 15). Heidegger realizes this interpretation of human existence through the analysis of Dasein, of which we must recall here some great traits.

For Heidegger, being is the culmination of all human impulses. In his text titled Introduction to Metaphysics, he states that the fact that we understand being, even if in an indeterminate way, is what occupies the highest rank, for our being-there, in so far as it reveals a power in which resides the essential possibility of our be there (Heidegger, 2000).

In this perspective, man can understand his own being only in the understanding of being as such; it is only by appreciating the pre-eminence of the understanding of being that we maintain it as eminence. Without one (such) opening of being, we could in no way be "men". So, it is by its essential relation to being in general that being-There is itself because the existential essence of human is the foundation by which he can represent being as such and have an awareness of the represented. Heidegger thinks of being as the vocation of human. He is nearer to man than to all beings, for man has a prior agreement to be so. Human is destined to be so, but being is kept alive and present only by man.

Human thus constitutes the shepherd of being. Its existence has the function of ensuring the guard of being and thus assumes its being-thrown into facticity, as a place-holding of being. In other words, being-man is to assume the recollection, the gathering apprehension of the being of the being, the implementation of the appearing by the knowledge, and thus to manage the non-latency, to preserve it of the latency and of buckling (Heidegger, 1962).

Therefore, according to Heidegger, the meaning of being belongs only to the specifically existing being, namely the Dasein, who is in such a way that being he hears something such as being, since the question of being is then nothing other than the radicalization of a tendency to be belonging in essence to Dasein himself, the pre-ontological understanding of being. In the end, to ask expressly and in all clarity the question of the meaning of being, it is necessary to pass first by an explanation of a being (Dasein) by considering precisely his being. Being, by its light, makes possible any experience on being. The light of being is the condition of possibility of the experience of being in thought. "According to the analysis which we have now completed, Being with Others belongs to the Being of Dasein, which is an issue for Dasein in its very Being. Thus as Being-with, Dasein 'is' essentially for the sake of Others” (Heidegger, 1962: p. 160).

These analyze of Heidegger show this: understanding is synonymous with human existence as such. Now, since Aristotle, comprehension is aimed at the universal or the general, for there is science only of the general. If being is the general element of beings, its comprehension by a particular being, namely man, raises a question of substance: what about universal reach of this understanding? In other words, in the name of what would the universal understanding of a verb (being) be the locus of the truth of the human being? 
In terms of development philosophy, it would be to admit that the man enters the process of its development when thinking being. Development is considered as the fact of assuming the authenticity of our essence or of what is our own. But the fact of raising the question of the possibility of not thinking about being shows that only the philosopher (Heidegger) considers the thought of being as a vital concern. The thought of being does not therefore come from ordinary human experience.

Therefore, how to found the humanity of the human being on what is only the peculiarity of the philosopher? It is probably appropriate to recognize with $\mathrm{E}$. Levinas that ontology is not fundamental. According to Levinas, the Heideggerian discourse of understanding is in the direct line of the traditional articulation of the particular and the universal.

The taking into account of anthropological primacy in philosophical research concerns precisely the surpassing of the subjection of the particular to the already universal discourse of the comprehension of being. The question that serves as the backdrop for this overshoot is this one: who decides the understanding of being? Who places the primacy and priority of a philosophical discipline in relation to others? The question who questions in relation to the very one who questions and seeks, namely the human subject: what about the subject himself in his concrete humanity?

To pose the primacy of the human subject who questions himself is to recognize the fact that the problem of the foundations of the first philosophy, the mother of herself and the mother of all sciences, awakes only in the evening, after a day's work: older is the incarnated subject, older than any knowledge and any questioning on knowledge. Incarnation is not an external juxtaposition of objects, but is the fact to be in another than oneself, as indicated by "in". However, to be "in" does not correspond to a contained-content relationship; consciousness is not contained in the human body in the manner of a liquid in a vase. It is the man who, in his deployment, lets emerge self-awareness.

Consciousness, insofar as it has no expanse, is an event of subjectivity; it occurs when the subject becomes conscious of himself, when he feels himself already existing there, posited, where the already indicates the time of the position and the domiciliation in the domain of being. Consciousness always and already late compared to the man as subject who carries it, conscience in spite of itself. Self-awareness is not the exhibition of knowledge or the fact of being born with oneself (knowledge), but a test of sensitivity is feeling oneself at home.

Henceforth, the search for the beginning of all philosophy in general is certainly first, but of a primacy already enclosed in the game of the formal axiomatic, in which the meanings that attempt to transcend an axiom are based on this axiom. The ambition of the subordination of all philosophy to a first philosophy is based on this function of logical deduction, whose axiomatic displays legitimacy. But the meaning, which comes directly from the structures of man as a subject, interrupts the axiomatic deduction, so that the relation first philosophy 
and second philosophy no longer rests on a dialectical structure of propositions. It is the human subject, more than the deduction of categories, which gives a foreword to all philosophical discourse and, consequently, is the first.

We therefore start from the consideration of the primacy of the human subject in first philosophy, to establish the foundations of the anthropology of development, understood here as a second philosophy, and oriented towards a philosophy of novelty and the human quest for well-being.

\section{The Idea of Well-Being}

The anthropology of development, in the philosophical way, is based on a certain theoretical conception of well-being. This is to clarify this theory, showing both the individual and social dimensions of the good life. The idea of well-being supposes the existence of a conscious human subject, capable of giving himself a project of life, within the limits and possibilities offered by the social context. The proper meaning of the notion of well-being, from the point of view of fundamental philosophy, arises with the phenomenological analysis of the experiences of the consciousness of well-being. From this point of view, it departs from any idea of quantification and qualification (measurement). Indeed, the extent of welfare calls would search its index, which would cross the expectations and desires of individuals to acquire property, previously recognized and defined. And property, to such an extent, would be all that relates to wealth and individual freedom to act. To establish, in this perspective, what would correspond to well-being, it would be advisable to go through a survey of opinions, according to the probabilistic rules of the statisticians. Such a survey, to tell the truth, is not operative in philosophy.

Philosophical analysis attempts to pose the general concept of well-being in its own phenomenon. The question to solve in philosophy is this: towards which place our ideas converge, when we think about the well-being?

If in the word "well-being" there is the word "to be", his phenomenological description is not to say that "well" Is this or that, because "being well" escapes all indications pronouns. We must turn the eye of understanding towards the "well", below the "to be" to see the conditions of the coming of the good life to the "being". In a word, well-being is development as such. This identification must be made explicit, through the return (reduction) to the common sense of the notion of good. To achieve this reduction, we need to call the Heideggerian notion of the world, understood as the network of utility tools. According to paragraph 18 of Heidegger's Time and Being, the tool or being available is all that man uses to live. Each tool gets its turn according to its end-determined utility as the possibility of Dasein as an authentic and unique end (Heidegger, 1962).

Every act and every object of the act is at once the means and the end. Not only do I use the pen to write a letter, which is the means of communication with others, but I also enjoy the pen and write a letter without always thinking of the end. In this way, the act and the object are no longer means but the end. It is the notion of Heideggerian end, understood as enjoyment that we interpret in 
terms of goodness.

The end is not only the being of Dasein, but what he sees as his good, and he enjoys it. Well-being, in this sense, refers to an intentional act. The aim of a good life is the process of the return to oneself, in view of what one aims as a realization of oneself in the enjoyment of an object.

This return to oneself is the condition of possibility of the reception of the world within oneself. In this way, the good requires a double intentional movement: that of the exit from oneself for the conquest of things (or foods), and that of the return to oneself to assimilate what is conquered. It is the first moment during which the subject comes out of oneself, since it is not the world. Thus, well-being, within the consciousness, is the self conceived as presence to oneself or presence in oneself, but in the other. I advocate the well-being by associating it every time with something other than me, with the air that I must breathe, at rest after a work, with the glass of water which must quench my thirst. All of these things are embedded in me. What I live does not enslave me, I enjoy it. The happy self is the one who remains in a postponement of satisfaction, who dwells in a certain way in the object of his enjoyment.

Enjoyment is comparable to an intentional project, but without a determined rationality as a deep aspiration. The realization of a happy life is played out in the permanent and conscious presence of the object of enjoyment, before being projected, externally, towards the realization of a fixed and determined life project. Here we must take the term project in its sense to throw ahead. What is thrown is within the consciousness of the project, and its temporal realization is an intimate work of consciousness.

This analysis goes beyond the consideration of the good as a need to be satisfied, and tries to emphasize the root of the consciousness of good. It is therefore not a question of establishing a hierarchy of projects to be carried out according to the needs. It is rather a question of stopping on the moment which corresponds to what we live under the mode of happiness. Indeed, it happens that what is expected, in the order of the satisfaction of a need, does not produce, once present, a feeling of happiness. It also happens that what is not expected, on arrival, produces joy. This is probably linked to the dimension of the unknown that characterizes what will happen.

Thus, the analysis of the moment of enjoyment has the advantage of revealing what should be called the essence of well-being, which corresponds to a specific intentionality of enjoyment. But the intentionality of enjoyment represents a radical inversion. It is the body, the first element of this exteriority (or openness), which arises and stands in the world, and all the existence of the ego is at first in this posture of the body. Bodily existence is the place that carries the elements of enjoyment.

The body allows the interiority of the enjoyment of goods; the self is of the kind at home. Enjoyment, which is not conservation proper and even less technical use of things, is not free consumption either: it is inseparable from pure 
sensitivity and quality. The ego of enjoyment is happy in its joy of breathing, of seeing and feeling, of standing in the world from within, of attention to oneself, of intimacy which is the anchor even of his ability to go out into the world. To enjoy is to exist by recollecting oneself, separating oneself from the world from a friendship with oneself.

The constitutive consciousness of the subject does not hover in the ethereal sphere of an ideal world; it is lodged in a body. From the moment consciousness awakens to corporeality, the body lends meaning to sensibility as the birth of the self or the movement of the return to oneself. Sensitivity is the genesis from which everything happens in us. Understood in this way, sensibility is not always subordinated to the objectifying act. The epoch of objectivity, which produces pure sensibility, accomplishes the reduction of space and time to the dimension of here and now of the living body. It is possible to distinguish the sensible as such from the sensible as matter or quality from the perception of object that would fill the empty intentionality. In other words, the sensation is to be distinguished from perception.

The sensation is not aimed at anything. The sensation does not follow the rhythm of the intentional consciousness; it does not relate to an object, it does not lead to a representation. It is in its title that it is in the enjoyment, understood as contentment of things. To live with things is to be content with things, to let one go to them, and let them come to you. Sensation as enjoyment is the passage of life in the body and passage of the body in life. And sensation is passivity, whereas perception is an experience that tends to constitute a representation on the basis of sensible experiences.

A gustatory or olfactory sensation is not primarily the knowledge of a flavor or a perfume, or the realization of a life project. The opening on the flavor is enjoyment. The taste sensation does not have the distance of knowledge, it is satisfaction. To savor is to assimilate. In this sense, well-being is in the "savoring", as a pure sensation in an instant.

In short, the link between the good, the enjoyment, and the interiority of the consciousness, the pure sensibility and the body allows us to say this: well-being is an immanent sensation that escapes all representation and all knowledge. The singularity of the subject manifests itself in the fact that he enjoys the world. But he cannot enjoy it immediately. He must recollect himself in the tranquility of the body where he can take possession of his own enjoyment. Thanks to the body as a possibility of possession of external things, the ego can take possession of what it feeds on-the world being considered as a set of foods or objects of enjoyment. By possession, man removes from his natural place that which is external to him, and adapts it to his own body. Possession is the reduction to oneself of what initially appears to be external. By possession, the world becomes a world invested by the will of the subject, by his project, and thus worked by his hands. The world is adapted through work. It is therefore appropriate to say that the subject takes possession of the world through work. In this perspective, the 
work is a figure of the possession, and instance of transformation of the objects of enjoyment. Enjoyment is the selfhood of self or the return of me to $I$, in contentment.

This phenomenological and eidetic analysis of the good already allows us to remember that well-being, recognized as an index of human development, is found in the enjoyment of the world, within itself, in every moment. To develop, in this perspective, is to create the conditions of possibility of such enjoyment. But enjoyment, insofar as it is realized in the double movement of exit and return to oneself, integrates a dimension of otherness (of the world) which modifies the ontological structure of the one who enjoys by posing it as being at home in something other than oneself. To enjoy the other (of the world) therefore operates a change in the one who enjoys.

\section{Development as a Positive Change}

The analysis of the concept of development in philosophy must be made in the light of this understanding of the phenomenological well-being or, in the words of Fink (1974), in the "idea of an original theoretical state". We must therefore extend the analysis of sensibility and enjoyment to the original understanding, with a view to giving it a philosophical stature as such-on the understanding that the philosophical has appeared in the understanding. The return to the originally takes place in the taking into account of our dimension of subject capable of knowledge (anthropology).

Any philosophical approach is based on the search for a general or fundamental knowledge of the essence. To gain access to such knowledge, one must first break away from the apprehension of oneself as a definite subject for all of its dependencies on the world, nature and society, his familiarity with his surrounding and familiar world to appear as a knowing subject, attentive to the world in and of itself. The demand for attention to the world as it is given leads to the understanding of it as a question.

To wonder about the world is to be surprised that there is a world and that the subject is already there. As a result, the question of the possibility of franking as development requires that the presence of the world be a problem. The radical question is this: how can I transform from me a world that is outside of me, without being satisfied with its mere enjoyment?

The proper answer to this question can only come with the exit of the static conception of the world which, at bottom, is a form of first naivety. The break with naivety is the infinite task that defines philosophy in its own right. To leave the first naivety is a true conversion allowing being in the listening of the world in its own movement. It is about getting out of blindness rather than learning to see. The crossing of the first naiveté is thus at once ontological: to learn to see is to learn to be astonished, not of this or that aspect of the world, but of the world in its totality, to say of the world as a world. It's about letting the being of the world unveil itself in its truth. 
In other words, the necessary condition here is to get rid of the usual representations that determine what is meant by world. The philosophy of development in its many descriptive possibilities will be true to itself only in so far as it remains faithful to this requirement of all philosophy.

To begin the crossing of the first naiveté, let us take this word from Henri Bergson, delivered at a conference in 1911 at the University of Oxford: "It is enough to be convinced once and for all that the reality is change, that change is invisible, and that, in an invisible change, the past is one with the present" (Bergson, 1938: p. 173).

In quoting Bergson's word, we mean this: reality is identical to movement or change, and the present is inseparable from the past. The movement is thus attached to a certain conception of the present time and duration, and it is not the path of a space or the geographical displacement of objects. More precisely, movement consists of the passage from the past to the present.

But since the past is an ecstasy of time and not a thing, its passage into the present is an operation of human consciousness. We have the consciousness of change, when we keep past events in consciousness, events in their historical effectiveness. But to become aware of these events is to bring them back to the present, to us. It is the human being who, in his consciousness, recognizes that what is here now (present) was first there (past). Our consciousness is thus able to define the movement itself, without relating it to the change of a thing, thanks to the category of present time of consciousness.

It is also in the present of consciousness that we foresee the future, as what has not yet happened or what will happen. If the transition from the past to the present is change from what we are experiencing, the future is change from what is happening to us. And development would be positive novelty.

We need to start from the Bergsonian conception of time as duration, to think about human development, and to cross the Blochian conception of the New. The duration is what the reality overflows with possibilities in the experience we can make of our inner self or life, considered in its evolution.

In this perspective, development is not primarily a quantitative accumulation or an exponential widening of reality. Development is rather in the dynamics of our inner life, so that the transformation of the world is only the externalization of this interiority.

The concept of human development, conceived in its own essence, suggests the idea of innovation, in the sense of entry into the new (in novum), transition to what has not yet been. Insofar as the novelty is shown in the light of the non-place, apart from any rooting and any domiciliation in the here, it coming is ex evento. The non-place is not the absence or lack of place, but the other place, which is beyond the place; and the novelty, comes from the future as such, without having foot in being, its essence is to come.

In this perspective, thinking about human development, is to try to escape the site of the current realities and his draperies to utopia any better place to come. 
We can therefore understand why the thought of development is possible only if thought itself is welcomed as development. Thus, the philosophy of human development is a reception of the utopian exteriority or the disruption of the history of traditional philosophy, by the coincidence of the past and of thought, by going beyond all attempts to rest from what is posed.

Thinking about development is therefore a mental conversion which, in a negative way, is an effort to say nothing more than simply being posited in the status quo or crystallized in the usual. It is necessary to unmask the historical reality so that the being riveted to oneself of the present life opens to a better situation, otherwise. We must destabilize the present of our history so that it does not rest in peace under its identity of despair.

It is a question of renewing the historical situations to formless materiality or the indeterminate utopia, and to hear hope as what is stated in the hope of being such. Hope, as a means of tending towards the other place that comes, creates a dimension of meaning different from that of the thought of "the eternal return". To think that reality does not change is to place oneself in the perspective of the nostalgia for paradise, which has always been lost, a nostalgia that empties the history of its reserves of possibilities and all forms of future.

But the future in history is what indicates the New, understood as the thought of a better life with others, in a just society. Thus understood, the New has an ontological character which can only be grasped in a negative sense, namely the non-still-being. The novelty is in what is coming and not yet there. This negative character is not related to the novelty itself, but to the awakening of the human conscience which recognizes the insufficiency of what is present and tends towards the best to come: the novelty is in the future, that is irreducible to the pure presence.

Ontological negation in the ontology, the newness appears when the being in act reaches its limit of being, and passes the witness in the future (to be in power), as ground where arises what comes to be. To come to rest in being, that is, without being confused with the present, to come into the stature of the event, such would be the novelty conceived as the essence of the new and of development.

The essence or the visibility of the phenomena is shown as the name of a predicative proposition. And the novelty is the essence of the new, when it is recognized. Applied to the movement, the novelty is, exhibiting development or positive change, but this new exposition is the exhibition of novelty itself.

As a result, human development is synonymous with the advent of the new in consciousness. If the new appears as such only by aging the old, rendering it obsolete and old, it corresponds to development only when it is recognized by the human conscience as advanced towards the best. But to hold the New does not consist in bringing out ideas of nothingness. One is mistaken about the concept of novelty if one takes it for the most modern of the modern, for the progress towards what never existed.

The concept of modernity is the other name that qualifies the appearance of 
the new in human societies. From the point of view of the thinking subject, modernity is the anticipatory awareness of future possibilities. In this sense, it comes at once from the order of reason and from the order of desire, when these two orders seek creativity and novelty.

As a place of emergence of the breaking factors of the traditions, modernity is a celebration of the new from the old, a kind of creatio ex vetere, of creation from the old. In the fabric of processes that constitute all human society and its history, modernity corresponds to a new state of affairs.

The philosophy of human development should stop, in the first place, on the development of philosophy itself, in order to grasp, in this development, the conditions of a full assurance of its task in the concert of human activities. It is not a question of describing the evolution of the philosophical thought according to its different currents, from the origins to our days. It is rather a question of placing development as the place of articulation between thought, thought and the thinker, given that the novelty here is in thought as a quest for new knowledge.

\section{Discussion: The Good Life and the Human Nature}

Philosophy is, in itself, a desire for truth and deepening of knowledge. Such desire is a renewed passage from the incompleteness of ignorance to the fulfillment of man as a knowing subject. In this sense, to know is to develop or crossing. It means that the human being fully fulfils his nature only when he is guided by thought, so that his well-being is linked to the realization of what he thinks.

Whether developing human and social corresponding well-being, E. Bloch the claims in these terms: the better existence is first of all in the thought that we lead it (Bloch, 1986). To lead the better existence in thought is undoubtedly to remain in the heritage of philosophical thought, to withdraw from it what can contribute to a spiritual innovation, in the present of history. Such a stay is an existential activity. The first one assumes one step only and then one; first in thought and then in the social and material organization of life. For this reason, a desirable society (Bruce, 2016) begins with the individual development of the ability to think the best in oneself and around oneself.

The best existence is conducted in thought when the human being has within himself to establish what he wishes the best for his whole existence. It is the thought of the ideal of a good, imaginable and desirable life, with that entire one can have as energy and inner resources to project oneself towards an ideal of life.

In order not to cross the time of his earthly existence like a traveler without luggage, feeling alienated from his own skin, as in a borrowed existence, the human being gives himself content to his existence by way of reasons to live. To live "for", to live "in view of", would be the ontological structure of a human life authentically assumed, in the way of anthropological development.

We must first think, and the thought itself is a primordial way to exist (ex sto), to always stand out of oneself, to be preoccupied (occupied in advance), to go 
ahead of itself. Existence, in the order of thought, as crossing, is not a movement from within to the outside of the thinking subject, but a return to itself; it is a relation of the self with one's self, the link between a subject and the verb to be. But existence in general is the action of being; and the "ex" of the verb exist indicates, not the exit of the subject to an elsewhere, but the emergence of the existent from the instant: to exist is to stand in the moment (now), to assume the anonymous being is the fulfillment of the nuptial pact between the self and the being, an accomplishment in which the self becomes the subject of the verb to be and can say "I am".

But to think, in truth, is to strive for the best in ourselves and in the world. In a word, thinking is a quest for the best in all things. And the best here is understood as the fulfillment or realization of one's nature, that is, for what one is born. Birth or coming into the world involves an ontological determination of the order of meaning and purpose that must be interpreted in terms of nature. If the finish is to finish one day, it is actually when it finishes that it reveals its finite nature.

This understanding of nature refers to the $\varphi v \sigma \iota \varsigma$ (physis) in Aristotle. Certainly, Bloch does not propose a theory of nature as such, and in The Politics of Aristotle (1999), the concept of human nature is associated with the construction of cities and human life in the city. For Aristotle, in fact, the ultimate purpose of man is to live in the city. But it is possible to interpret the Blochian idea of better existence from Aristotle's understanding of nature, by identifying "better" with "finality" and, according to the openness we want to highlight, finality is synonymous with development. From then on, the "better existence" conducted "in thought", such as E. Bloch conceives it, would be the reflection on the citizenry, under the species of human nature. But let us begin by clarifying the outline of human nature in Aristotle.

According to Aristotle, the nature of a thing is its end, since what is each thing once it has reached its full development; we say that this is the nature of the thing, as well for a man, a horse or a family (Aristotle, 1999). Nature is the finality or the full development. Aristotle reaches this conclusion after observing the world and everything in it. This experience of the world, accessible to every human being, consists in the recognition of the positivity of the world. The Aristotelian approach, qualified by the philosophical tradition of realism, starts from the analysis of what exists as given, in order to discover, in the second place, the general principle on which it is based.

Indeed, if we close our eyes and then open them, we offer ourselves an original experience, that of a positivity, namely that things are and they are above all else. If the world is here comparable to the set of natural things that exist, it is what has arisen before us, outside ourselves and without us. Things are given a priori through the category of being. It is therefore appropriate to say this: is what is there. The "there is" is the mode in which is collected what is: there is this, there is this tree, and there is this river over there. In this perspective, thinking is to recognize the "there is", and to enter the world and things without 
prejudice, but the opening to the idea of development occurs when one experiences a form of dissatisfaction with what is already. Things may be there, it is possible to consider a better always absent, a better who is beckoning in what is there, while remaining ahead.

The thought of development, from the point of view of the philosophical act, lies in the recognition of the inadequacy of being. The idea of development is thus opposed to that of the self-centered, hypostatic being, whose only horizon is the organization of its train of being. Such a being, indeed, since Aristotle, is reserved for the autarchy of lifeless divinities, pure thoughts which are taken for objects of thought. But being available to human thought is the one that comes to the idea, from our encounter with the world.

Adhering by simple impression to the truth of the world as "there is," as a publication, is to recognize the primitive truth, the abyssal base, the substance of everything, the principle. There is always something going on. Something starts; something is there, something that ends. The beginning and the end translate the two poles of the movement. What is subject to movement and to change?

In the philosophical tradition coming from Aristotle, movement is the expression of the materiality of bodies. Only what exists under the expression of the way changes, because matter is the substratum of change.

In the first book of Physics, Aristotle sees nature as the set of things that move (Aristotle, 1991). For this reason, movement is the starting point for any scientific explanation. Aristotle defines movement as the act of the possible.

We must go back to the explanation of form and matter to grasp this Aristotelian formula. Matter is the indeterminate; on the contrary, form is what determines being and does what it is. There must be a movement for form to join matter. To the extent that motion is inseparable from things, the change of being is produced in the substance, quantity, quality, and place of being. Now being either real or simply possible, it is the transition from the possible to the real which constitutes the movement.

There is therefore movement or change, whenever there is the act (actualization) or the realization of the possible as possible. For example, the bronze is the statue in power, that is to say that the bronze can become a statue; but it is not as a wind man that he is set in motion; it's only as mobile. The movement takes place only at the moment of the act; there is neither before nor after. The act of a house that is to be built is construction; before the house is built, there is no movement yet; it is simply possible; after it is built, there is no movement.

That matter is what defines the passage from the possible to the real, from the power to the act; Ernst Bloch recognizes it by bringing it to its most materialistic interpretation. The real possibility, understood as a dialectical matter, is, according to him, the logical expression of material conditionality sufficient on the one hand, of material openness (matter being an undrawn lap) on the other (Bloch, 1986). E. Bloch favors what should be called a materialist interpretation of the possible Aristotelian, without insisting on the form and the act. $\mathrm{He}$ asserts that matter, in Aristotle is the undrawn lap of which all the figures of 
the world come out. The taking into consideration of what is to be achieved at such and such a moment is based on the being-according to the possibility of matter, the well-founded expectation of accessibility itself is based on the being-in-possibility of matter. The trinomial to be retained here is: possible-expectation-material.

If the better existence is the finality targeted by all human life, if this end is development, understood in its human sense of self-realization by thought, before any social organization, any production of goods and their consumption, the possible and expectation must be grasped in their material dimension in order to ground the concept of human development, in the sense of novelty. The materiality of expectation and possibility cannot be reduced to the sedimentary solidity of what crystallizes and settles. Is material, all that goes towards an accomplishment or a realization. And the realization is the coming to the state of thing (res). In Aristotelian terms, this is what can pass from the indeterminate to the deterministic. Thus, possible, expectation, matter, without being synonymous, have a common trait, namely the path to novelty recognized as a plus-being, openness to the best, taking the thickness from oneself.

The possibility, associated with a coming, is translated into waiting: waiting for this or that, waiting for the expected. And the waited has the function to give content to the waiting. The expected always appears as a positive change from what is already there. But the expectation here is aimed at the general, and concerns the possible attached to human projects. From the point of view of time, the expected is related to the figure of the future, while the consciousness of expectation, like all consciences, is experienced in the present. To wait is therefore to live in the present the premises of what is to come.

There is pending a kind of knowledge that indicates that with the effective arrival of the expected, the wait should end; as if the end was already known, and this end would correspond with the presence, finally, of what was expected. But the point of waiting is mainly in the mobilization of psychic energies towards a horizon. It is undoubtedly this mobilization of energies which prevents the confinement of the waiting in the lazy passivity. It is also she who gives a temporal consistency to the possible, so that the waiting is waiting for the advent of the possible. And the possible being always wider than the real, the expectation is always submitted to a new, constitutive of the otherness of the expected. Indeed, the waiting is always waiting for the other hand, for this reason, it is subject to the difference of the other coming.

It would be necessary to multiply the exergues to give to think the enigma of what announces itself in the waiting. Waiting that has not (of) place, and the imminence of his coming is still to come. It is in this non-place that waiting is given to think like the torment of time. The non-place or the other of any place does not have to take place. With regard to utopia and waiting, it is in the discovery of the not-yet-conscious that expectation reaches the rank that belongs to it: that of utopian function, both in the affect only in representation and in 
thought.

The not-yet-conscious is involved in the turning of the utopia which, departing from the ordinary turn of events is made by him detour. It is the torment of time which, being always to come, comes as a novelty in the present, coming without coming into the patience of the time, an immeasurable time, destined for the intermittency of a disproportionate thought, and which is the silent stop of what, without obligation, it is necessary however to wait. Waiting is another time, an out-time in time to be able or possible.

It is therefore not a matter of locking oneself into a dreamy nostalgia for the paradise lost in the past, but of making it a living source for revolutionary action, for a praxis oriented toward the fulfillment of utopia. It is, all things considered, in the open of an anticipatory thought, entirely turned towards the world to come, with the critical look towards this world. The indictment of the industrial/capitalist civilization and its misdeeds is the matrix bottom of the expectation of the coming world. It sweeps from one of hand the pure disgrace and ruthless ignominy of today's business world, a world usually placed under the sign of the scam, in which the thirst of gain stifles other human impetus. It also attacks cold and functional modern cities, which are not homes but machines for living, which reduce human beings to the status of standardized termites.

As a result, waiting means, in this context, that any present situation is not yet the coming. The New does not correspond to a presence. He is in the midst of the event and the non-event, in a time more future than any thought can announce. It is in this "not yet" that one must recognize the movement of waiting or waiting as a movement. It is because the event of waiting precedes and calls the event. In this sense, waiting is synonymous with the expected future.

In other words, the expectation was to pose or suppose an end, this end would be endless. It should be further elaborated on what is meant by "endless end"; coupled with the problematic of development, "the endless end" says the fact that at any end there is a beginning: the end of one stage and the beginning of another, and so on, without end. But "without end" is not an opening here to infinity, but the one who waits dissatisfaction state.

Therefore, to the question: when wills the coming of the possible expected? The answer is: for today. It's my neighbor, without a stranglehold. There is no waiting, although it is an obligation to wait, but at the same time, what is already there calls waiting for another now. And when is it now? Now that does not belong in ordinary times, which necessarily upsets, does not maintain the destabilizing.

The urgency of such a "now" scansion that never makes this "now" a central point in the order of time, has no punctuality of a present now, a now "present" on the basis of which philosophical thought has always measured the concepts of consciousness, truth, subject and presence. Waiting as the humanization of the possible or the possible become a human desire for well-being, is a relation with the future, and its now is there coming. Now, as a relationship with the future, which, however, is the index of desire that is still unfulfilled, a tension towards 
what is coming.

Deference from the immemorial to the unforeseeable, the now of expectation is at once the desire for the best and the perpetual postponement of satisfaction. The expectation would be the desire for what comes, without this coming can be effective. Waiting for what cannot be term and which always refers to the best being. Always desire: length of waiting for a distance not measurable; relationship of deference to what cannot be represented and designated to the indicative.

Waiting without a single wait, but open to the possible, in all the length of time, attention to the unfolding of the lived life like tension towards the accomplishment of oneself. A confirmation of the time out of time, out of the present, which translates the truth of the human always in search of the best in oneself, for oneself and outside oneself. The waiting is allied with the extreme urgency, which does not settle in time. At the urgency, the time itself is missing. Breaking time and not only opening at another time. Lack of time, that is not the lack of something that one would lose or dispossess; lack of time as a desire to anticipate what must come, namely the better life.

These analyzes make it possible to see this: the better life is not a state of satisfaction in the permanence of the present. Development, in humans, is always to come. It is at this level that expectation intersects with the new, because what is expected comes under the species of the new, unpredictable in relation to the horizon of being present. What is expected comes from the future as such, without being rooted in being, because the future is its essence.

In this light, be waiting, is to try to escape the limited ground of being present to infinity of new possibilities. Only attention to the Beyond being present makes it possible to think of development as being better. Here, the thought of waiting is identified with the expectant, insofar as in it, the trace of what is expected lies in the vigilance of thought. The best way to wait would be to think the waiting.

To think of waiting as an effort to no longer read the present of human history as what is definitely posited in its being-there. The present, in its evanescence, is called to pass, and to pass the witness to another time which has never been present. It is a question of admitting the obsolescence of what is presented in the present to consider another present to come, presumed to be better.

The expectation is essentially prospective, because it opens a future and it is received from this future that it opens. It is emergence from nothing as a radical novelty, with the character of an absolute beginning. It is not possible until it is real. When it arises, it exceeds its conditions of possibility. It happens in addition to being.

It breaks all familiarity with the ancient world and exposes it to the risk of an otherness that escapes all control and foresight, upsets the possible, and implies the advent of a new story, that of the good life. As an opening to the possibility of infinite, the waiting is related to the indeterminate matter. To exist physically is to be subject to the possibility of being otherwise, changing.

Development, reduced to the realization of an individual desire-wish, remains 
in the sphere of the individual. How to elevate it to the social level of the universal common good? It should be remembered that the common good, in the scholastic sense of bonuses cummunis, is not the addition of individual goods, but the participation of individuals in a work of community interest, and this participation is a gift of self. The common good is not a thing, but the quality of an action in which an individual gives himself for the collective good. It is in this capacity that the articulation between the universal and the particular must be situated: an individual act can have a universal scope, when it is oriented towards the common good.

Thus, the universality of social development is realized as a peculiarity in the social action of individuals, as a singularity subtracted from egoistic determinations centred on the individual and directed towards the common good. The singularity of an individual action, aiming at the common good, refers to the community interest. The common good is therefore the space where each individual can exist in an ethical way, in the first sense of habitual residence. A human act is ethical when it strives for the common good and perm and the best integration of individuals into a community of life.

From then on, development is an ethical work whose object is the quest for the meaning to be given to human existence, the place where the awakenings of a good life are announced and transcribed with and for others. Give meaning to human existence by giving oneself, it is the movement toward novelty, which cannot enter in social effectiveness if it is assumed e a renewed humanity. The renewal of humanity happens through the new acts to be posed, in the face of the new possibilities of existence that open up to us. The man who enters the posture of a new humanity, recognized as an index of human development, adopts a specific way of acting. He declines his identity where his historical action is articulated and the truth of what he is. This articulation is the criterion that allows the recognition of the development process.

The novelty in man, coupled with the development, is not the fruit of an ontological transformation, but it comes from the new way of living the temporality, to actualize the possibilities of acting not exhausted in the past, with a view to extending them into a future bearer of well-being. It is basically a way of life that is rooted at all times in the expectation of the coming of the desired and desired world from us. Indeed, human development, in its plenary form, integrative figure of all better life, will not happen without us. His future as it is in the promise that door our good life images-wishes, is given to our active consent, to commitment to our freedoms: human development is our task and our praxis.

Thus understood, human development follows the movement of a certain humanization of man, so that any understanding of human development and any understanding of mankind's humanity takes place within the historical framework determined by social praxis. The meanings of the human being are organized, from the point of view of development, in a structural field where they are ordered to the idea that one has of the man, and to the finality that one 
gives to his existence. To develop means to develop and humanize oneself, that is to say, to walk towards what we consider as the path of self-realization within a human community.

A question then arises: where can one observe, in the real life of peoples, such praxis of humanization? This praxis is observable when one agrees to revaluate human history or the unfolding of human life in time, through gelatinizing which, within any historical presence, indicates and works for what is not yet. Such relativisation allows the insertion of tension within certainties and opposes any form of one dimensionality.

Relativisation in this context means to conceive of human existence, not as a closed totality, but as a goal, a possibility. The dialectic to consider here is this: life this e is moving toward its own transcendence, to the emergence of possible a better life. And the better life is already affected as a presence within the historical immanence, through the human acts that try to multiply the possibilities of well-being of all. The hinge of this dialectic is called waking dream, according to the word Bloch; an awakened dream that opposes any form of soft crystallization to the solicitations of the world and history.

Humanization and development goes by the assumption of daydreams that put this in question, that awaken the dormant hopes that open future horizons and call to action.

\section{Conclusion}

The philosophy of human development treats the actual contribution of the same with the world; this is the place and the condition of the existence of human being. The question of the relation of human being to the world is divided into three essential aspects: the report with reality, the relation to time, and the relation to others. It is also called the question of the origin and destiny of the human being: where does human being come from? What is the purpose of human being? Finally, it is the theoretical foundation of the idea of a development which presupposes that men set goals, gather the conditions of their achievements and arrange what is at their disposal to produce the desired effects. Our study leads to two major contributions, considered as two laws in philosophical anthropology of development.

1) The relation of human being to reality is divided into affects (which acts on us unconsciously) and perceptions (which is perceived consciously). The excess of what appears in consciousness does not correspond to the gap between intuition (as the core of explicit meaning) and the intention (the implicit field), but away from the act of knowledge and the ontological background that arouses it. This understanding of the human subject raises individual well-being, as enjoyment and, as such, ungraspable by any forms of life projects, of an economic nature. The enjoyment is pure sensitivity attached to the moment of its production. Thus, individual well-being can only truly be described when it is experienced, and it appears at that moment as an absolute sensation without intelli- 
gibility. It is therefore necessary to differentiate between well-being and the desire for well-being as a life project.

To desire a well-being that is not yet there, in the fullness of sensation, my desire that is actually desired is to project oneself into a better life, with uncertainty as the only guarantee. The project of life is structured, at the mental level, in image-wish, in the present of consciousness, and raises percepts, without an unfolding in the ordinary course of life. It introduces a gap between the original and the original, an offset that produces a split in the origin of desires.

The origin is pure gushing. But it is, at the same time, the place where something proceeds. We can thus distinguish two dimensions in the origin: the pure gushing distinct from any cause (event) and the something that comes from the origin. To desire a well-being is to be originally self, but not originally, because the subject who wishes is always and already behind the actual event of the desired well-being, he is not the cause. From this event, according to the enjoyment depends on an external element, it is the enjoyment of a good, different from the subject who enjoys. Enjoyment is a primary event on the basis of which individual well-being must be determined and understood: I sometimes experience a certain well-being because I enjoy a good, in an instant.

In this perspective, to enjoy is not to be the measure of the occurrence of this event. Enjoyment occurs to me without previous measure. The fact that well-being is given to us by sensation introduces into existence a heteronomy of consciousness. The consciousness of enjoyment is not an awareness of something, but a pure savor that ignores the limit of time.

2) The relation of man to time, the bearer of development, refers to a lived, experienced time. This is assuming the present time as being of future, to mature in future project. The concept of the future, like that of the present, is linked to the events, as things to come, nature unknown and, as such, leaves an opening to the new and unpublished.

The time of development is a tear that highlights the "already" accomplished, the "not yet accomplished" and waiting. Waiting is not a state, but a process, in the sense of the advents, to happen. And the future gives rise to the possibility of a new human becoming. Existence is both non-being and being, becoming perpetual and retaining time.

To think of time as waiting is to recognize in the real, the elements of walking forward, already in preparation, without a spatial and rectilinear conception of time. This means going beyond the fact of seeing in time only a linear continuation of the past, the present and the future, to grasp time under the "already" and "not yet", the accomplished and not accomplished. This conception of time makes it possible to reject the idea of a homogeneous time, of which all moments would be equal and additive, adding to each other according to the law of an endless series.

The reading of time in "already" and "not yet", in accomplished and unfulfilled imposes another evaluation of the present, as the time of transformative 
praxis, within which the unfinished in life is under 1 has mediate of human action. To grasp the present as a process, to search in the present for already and not-yet-accomplished elements, means to treat the temporality from the angle of the New; because the New is what needs to be done. It is from what is already accomplished in time that can be read the novelty of a "not yet". The emptiness or incompleteness of temporal phenomena can then be thought of as an opening beyond contents, a mode of relation with concrete utopia.

Human development genuine reliable is not purely economic and social, not merely apolitical but is born in a context where subjectivity is recognized as a host, as one that welcomes others and allows the passage of the policy to the already non-economic. Politics must therefore be subordinated to an injunction that goes beyond the political order. The language of human development is said in the reception of the other as another: development of the human or humanity which is the other in us. Development is the humanization of man or becoming human to the end; and this humanization consists in making oneself other, in a course of mediation of oneself. To be the condition of the mediation of one's own journey is to place oneself in the place from which one's life is organized, to constitute oneself (the human body and the built house).

\section{Conflicts of Interest}

The author declares no conflicts of interest regarding the publication of this paper.

\section{References}

Aristotle (1801). Metaphysics. London: Davis, Wilks and Taylor.

Aristotle (1991). Physics. Princeton: Princeton University Press.

Aristotle (1999). Politics. Kitchener: Batoche Books.

Beland, D., \& Cox, R. H. (2011). Ideas and Politics in Social Science Research. Oxford: Oxford University Press.

Bergson, H. (1938). La pensée et le mouvant. Essais et conférences. Paris: Presses Universitaire de France.

Bloch, E. (1986). The Principle of Hope (Vol. 1). Cambridge, Massachusetts: The MIT Press.

Bruce, C.-A. (2016). The State of Development Studies: Origins, Evolution and Prospects. Canadian Journal of Development Studies, 37, 5-26.

https://doi.org/10.1080/02255189.2016.1135788

Fink, E. (1974). Phénoménologie. Paris: Editions de Minuit.

Heidegger, M. (1962). Being and Time. Oxford: Blackwell Publishers Ltd.

Heidegger, M. (2000). Introduction to Metaphysics. Yale: Yale Nota Bene, Yale University Press.

Kant, E. (1819). Logic. London: W. Simpkin and R. Marshall.

Kothari, U. (2005). A Radical History of Development Studies: Individual, Institutions and Ideologies. London: Zed Books.

Levinas, E. (1993). Entre nous. Paris: Grasset.

Nussbaum, M. (1988). Nature, Function and Capability: Aristotle on Political Distribu- 
tion. In J. Annas and R. H. Grimm (Eds.), Oxford Studies in Ancient Philosophy (Supplementary Volume, pp. 145-184). Oxford: Clarendon.

Rist, G. (1997). The History of Development: From Western Origin to Global Faith. London: Zed.

Sen, A. (1999). Development as Freedom. New York: Knopf.

Sen, A. (2005). How Does Development Happen? Cato Journal, 25, 455-459. 